\title{
Commodity Trading Advisor Indexes And Alpha Generation Relationships
}

\author{
Scott Mackey, Roger Williams University, USA
}

\begin{abstract}
This research investigates the trend following relationships between Commodity Trading Advisor (CTA) Indexes and a widely known trend following proxy Index using a database covering 21 years with 24 CTA, Managed Futures, and Hedge Fund (that can trade CTA-like) Indexes. The trend following relationships are tested using a modification of the Methodology employed by Baesel, Gonzalez-Heres, Chen, \& Shin (2012). A unique Alpha adjustment is proposed to include the traditional Alpha plus or minus a reward or penalty for displaying relationships to the larger positive and negative returns of the trend following Index proxy. Results for the first sample period show evidence of at least some association of the returns of the trend following proxy to those of the individual CTA Indexes; however, most of the Indexes showed little to no statistical support for much traditional or adjusted Total Alpha generation. For the second sample period the regression results show that almost none of the Indexes had a statistically significant association with the monthly total returns of the trend following proxy Index. Instead, generally all of the Indexes showed the impact of the larger monthly returns of the trend following proxy Index such that the Alpha adjustments overall were positive and, on average, generated approximately 50\% of the Total Alpha of the individual CTA Indexes.
\end{abstract}

Keywords: Commodity Trading Advisors Trend Following Relationships; Commodity Trading Advisors Performance; Commodity Trading Advisors Alpha

\section{INTRODUCTION}

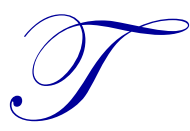

he purpose of this research is to investigate whether or not current Commodity Trading Advisor funds (CTAs) Indexes adequately capture the dominant trading strategy, trend following, followed by most CTAs documented in previous research. In addition, the leptokurtic nature of a trend following strategy fund's return distribution is examined in order to assess the potential impact of larger positive and negative return months on CTA Index performance. The well-documented leptokurtic kurtosis in CTA monthly returns is tested in a regression model using 21 years of monthly data with a total of 24 CTA and CTA-like hedge fund Indexes. A unique method of Alpha adjustment is proposed and tested to account for the effects of large positive and negative total return months to a trend following Index proxy. Specifically, the goals are to investigate three aspects of trend following: 1) the strength of the relationship of the individual CTA Index returns to those of the trend following Index proxy, 2) the impact of the larger trend following proxy return months on the CTA Indexes returns and performance, and 3) to attempt to explain differences in the results through investigations into the underlying markets and other analyses.

Many authors have produced research on CTAs, however, the first extensive research on CTAs are found in two informative papers, Fung and Hsieh (1997), and Schneeweis and Spurgin (1996), while a third, Spurgin (1999) offers important insights. These authors were among the first to document their findings on CTAs and the main findings of their research largely remain as mainstays of the literature. The first two papers chronologically offer common supporting results about the dominant characteristic of CTA trading behavior. The third paper offers some unique insights into CTAs and is an important source of understanding of both the underlying markets CTA funds trade in and how they trade. All three papers are discussed in chronological order. 
Schneeweis \& Spurgin (1996): In their study the authors used the same explanatory factors across three separate asset classes - mutual fund, CTA, and hedge fund Indexes - and find that different factors account for the return variation of each asset class studied. The returns to actively managed asset classes are assumed to be derived from four factors: 1) a natural return to owning financial or real assets (modeled as nominal values of indices of stocks, bonds, commodities, and currencies), 2) ability to employ both long and short positions in order to benefit from market timing skills (captured by absolute values of returns of underlying assets), 3) intra-month volatility (managers can profit from volatility by using either intra-month market timing or option strategies; modeled by intra-month standard deviation of returns of Indexes and maximum monthly draw-up and drawdown for each Index), and 4) market inefficiencies that result in temporary trends in prices (modeled by the MLM Index which captures returns to a trend following strategy). The key results for the CTA asset class include the following: 1) Trend following is the dominant strategy followed by CTAs as opposed to discretionary CTAs which can be described as market condition reactors, 2) results support the fact that CTAs do utilize both long/short positions and/or options strategies, 3) CTAs were found to be most strongly related to the trend following and the currency factors, and 4) CTA investment provides a diversification benefit to traditional stock and bond and perhaps hedge fund portfolios due to differential market environments in which CTAs earn positive returns; this is especially true for downward trending equity markets, e.g. CTA investment can provide a hedge against negative moves in equity markets.

Fung and Hsieh (1997): The authors' did have the benefit of several of Schneeweis et. al. papers in either "working paper" or "published" state while conducting their research, however Fung and Hsieh chose an entirely different focus using the method of principal components analysis to conduct their research. Their corroborating findings are 1) that there is one "dominant" trading strategy for CTAs and this is a trend following strategy, 2) they compare the dominant trend following strategy to systematic risk for CTAs, e.g. "analogous to beta" for the singlefactor CAPM model, and 3) the addition of CTAs to a traditional stock and bond portfolio would "dampen down swings (in addition to volatility) without giving up average returns."

Spurgin (1999): This author's paper begins by proposing conditions necessary but not sufficient to explain the positive returns to futures aggregate investors/speculators. These conditions lead to a series of testable implications which Spurgin conducts using CFTC commitments of traders' data for futures. A total of eight patterns are determined for segregating market conditions into "Rising/Falling" (trending) patterns or "Consolidating" (developing a trend) patterns. For the futures contracts tested (both "cost-of-carry" and "convenience yield" commodities), approximately $60 \%$ of the time the data indicated a "Rising/Falling" pattern while the remaining $40 \%$ of the time was classified as a "Consolidating" pattern. Spurgin developed a simple "trend following" and "responsive/discretionary" trading rule for testing as follows: 1) "trend following" - buy when prices are rising and sell when prices are falling, 2) "responsive/discretionary" - sell when prices are rising and buy when prices are falling, and 3) to summarize: the simple "trend following" trading strategy "is to be long when prices are rising and short when prices are falling so the following rule is used: buy if the current price is above at least two of the three reference prices (or all three), otherwise sell short." The main findings include the following: 1) most of the time the most profitable strategies were "trend following" as opposed to "responsive/discretionary", and 2) "In the context of the model, these stylized facts imply that hedgers are willing to offer futures contracts at a discount to expected value when prices are rising and sell them at a premium to expected value when prices are falling."

Since these three papers, there has been much research conducted and published, however, in the interest of the goals of this paper, readability, and space the interested reader is referenced to online resources such as Social Sciences Research Network's (SSRN) and Econlit's websites as well as proprietary databases such as EBSCO, JSTOR, etc. which one can access at any University library.

The balance of this research is presented in the following sections: Data, Methodology, Results, and Conclusions.

\section{DATA}

The data for this research was generously donated by the Center for International Securities and Derivatives Markets (CISDM) at the University of Massachusetts. The database contains monthly returns for traditional assets 
and Indexes, hedge fund Indexes, individual commodities, and commodity Indexes covering the time period from January 1990 through June 2011. A total of 21 individual commodity Indexes were collected plus 3 Macro hedge fund Indexes (some of which can sometimes trade similar to CTAs) in order to perform the analyses.

During the analysis it became clear that a structural break in the data occurred between the years 2000 and 2001 so the data was split into 2 time periods. Time period 1 covers the period January 1990 through December 2000 while the second time period covers the period January 2001 through December 2010; complete Index data ends in December 2010 for the database because not all Indexes have 2011 data available.

In order to conduct the regressions, complete time series of monthly returns is required for each of the Indexes. For time period 1, there are 10 Indexes with complete data and for time period 2 there are a total of 13 Indexes with complete data. However, all of the available Indexes were used in a later section when calculating the monthly return for the Portfolio of CTA Indexes which is used in further analysis and is simply the equal weighted average return of all of the Indexes with return data available for the month of calculation. All available data and data conforming to the two sample time periods for all 24 Indexes are shown in Table 1, located in Appendix A at the end of this paper, along with descriptive statistics. The descriptive statistics shown in Table 1 are for the entire database available at the time the analyses were conducted; description of details of the Indexes and other properties are covered in later sections.

\section{METHODOLOGY}

The methodology used by Baesel, Gonzalez-Heres, Chen, \& Shin (2012) (Baesel et. al., hereafter) is followed in this research though modified to fit the research topic. Baesel et. al. first segregate correlation data based on +/- 1 standard deviations from the long-term mean: "Low Correlation", "High Correlation", and "Normal Correlation". Once the data is segregated, the "Low" and "High" correlation data are run in a regime-testing model using dummy (binary) variables to isolate the specific regime. Finally, the coefficients from the previous regression are added to arrive at a Total Alpha value. In the current research, the same $+/-1$ standard deviation of monthly returns is used as the segregation point for the trend following proxy, the Mount Lucas Management Index (MLM Index), to isolate periods of "High" and "Low" performance under the initial assumption of return distribution normality (according to the MLM Index fact sheet, the distribution of monthly returns of the MLM Index is slightly positively skewed and leptokurtic). The Alpha calculation is the same as used in Baesel et. al. and is shown below.

Data Segregation proceeds as follows: first, use the MLM Index as a proxy for a trend following investment strategy, then segregate data into "Low", "High", and "Normal" periods based on +/- 1 standard deviations from the mean. The assumption of the shape of the total return distribution for the MLM Index is initially assumed to follow a normal distribution. This assumption is for two reasons: first, the emphasis is on capturing the effects of "high" and "low" total return months to the MLM Index (the trend following strategy proxy), and second, the actual shapes of the total return distributions for both the proxy and the individual Indexes are not known beforehand for the two time periods. To recap, a "low" return month is one in which the MLM Index had a total return value less than -1 standard deviation from the mean value; similarly, a "high" return month is one in which the MLM Index had a total return value greater than +1 standard deviation from the mean value. A "normal" return month is one in which the total return of the MLM Index is within the +/- 1 standard deviation from the mean value. The regression model is shown below as equation (1).

Regression Model:

$$
r_{C T A \text { Index }, t}=C_{0}+C_{1} \times r_{M L M I_{-} T R, t}+C_{2} \times I_{H I_{-} R E T, t}+C_{3} \times I_{L O_{-} R E T, t}+\varepsilon_{t}
$$

$r_{\text {CTA Index, }}$ : One of 21 CTA or Macro Strategy Index Returns

$r_{M L M I_{-} T R, t}:$ MLM trend-following Index Total Return

$I_{H I \_R E T, t}:$ Binary variable indicating a "high" MLM Index Monthly Total Return

$I_{L O \_R E T, t}$ : Binary variable indicating a "low" MLM Index Monthly Total Return

$\varepsilon_{t}$ : Error term, $\mathrm{N}(0,1)$ 
Within the investment community it is traditional to define Alpha as the intercept coefficient of a total returns-based regression and is often assumed to be the "return to skill" of an individual fund manager or even an Index; academics often think of it as that part of the total return of the dependent variable that is not explained by the factors of the regression model. In this research, Alpha is thought of along the lines of the "return to skill" definition where the underlying investment strategy is assumed to be predominantly trend following. This is not a good assumption for all of the CTA Indexes because some of them are specifically designed to track the performance of an altogether different investment style, e.g. the Discretionary Indexes. However, prior research has shown that the trend following investment style is predominant for CTAs so this style must logically be the basis for any meaningful analysis. For Indexes that do not strictly follow a trend following investment style the regression results should show evidence of this.

The basic Alpha value is modified by adding the coefficients of the binary variables of the "high" and "low" total return months of the MLM Index, the trend following strategy proxy, to the intercept coefficient (the traditional Alpha) to arrive at a Total Alpha value. It is expected that the coefficients for the "high" and "low" total return months will be positive and negative, respectively. The idea is based on the MLM Index description by the Mount Lucas Management website in which they describe the total return distribution as highly leptokurtic, e.g. peaked center and fat tails as compared to a normal distribution. Because CTA fund managers make ex ante long and short predictions on trend directions in the markets they trade in, sometimes they will be correct and be rewarded and at others they will be incorrect and be penalized. One of the unique goals of this research is to study the effects of the "high" and "low" total return months, especially the very large movements, on the resulting performance of the Indexes in the samples. The Total Alpha Calculation proceeds as follows:

$$
\text { Alpha }_{\text {Total }}=C_{0}+C_{2}+C_{3}
$$

$C_{0}:$ Intercept from regression equation (1)

$C_{2}$ : Coefficient for $I_{H I \_R E T}$

$C_{3}$ : Coefficient for $I_{L O} R E T$

\section{RESULTS}

The results for regression (1) for the first time period are shown in Table 2 shown below. It can be seen that for all of the 10 Indexes with complete data for this earlier time period the Adjusted $\mathrm{R}^{2}$ values and the overall regression F statistic are quite low; the mean values for both are approximately 0.05 and 3.2, respectively. Indeed, results for two of the Indexes show both very low Adjusted $\mathrm{R}^{2}$ values and regression $\mathrm{F}$ statistics that are either below the F-critical value (CASAM/CISDM CTA Asset Weighted Discretionary Index) or very close to the F-critical value (BTOP 50 Barclays US Managed Futures Index). The very low Adjusted $\mathrm{R}^{2}$ values suggest that for these two Indexes, and perhaps others as well, the linear model employed is incorrectly specified or there may be non-linear relationships involved possibly due to the use of options and other derivatives typical of many CTA fund investment strategies. The regression $\mathrm{F}$ statistic only indicates that there is strong evidence that all of the coefficients in the regression are zero; this casts doubt on the validity of the $5 \%$ level significant t-value for the coefficient, $C_{0}$, for the CASAM/CISDM CTA Asset Weighted Discretionary Index (all other coefficients are not significant at the 5\% level for this Index) and supports all the statistically insignificant coefficients for the BTOP 50 Barclays US Managed Futures Index. Finally, the CASM/CISDM CTA Asset Weighted Index showed slightly below average regression fit statistics but still showed no statistically significant coefficients. 
Table 1: Regression Results For Individual Indexes 1990-2000

\begin{tabular}{|c|c|c|c|c|c|c|c|c|c|}
\hline Index & $\begin{array}{l}\text { Adj. } \\
\mathbf{R}^{2}\end{array}$ & $\begin{array}{l}\text { Regr. } \\
\text { F-stat }\end{array}$ & $\begin{array}{c}C_{3} \\
\text { (t-stat) }\end{array}$ & $\begin{array}{c}C_{2} \\
\text { (t-stat) }\end{array}$ & $\begin{array}{c}C_{1} \\
\text { (t-stat) }\end{array}$ & $\begin{array}{c}C_{0} \\
\text { (t-stat) }\end{array}$ & $\begin{array}{c}\text { Alpha } \\
C_{0}+C_{2}+C_{3}\end{array}$ & $\begin{array}{l}\text { Alpha } \\
C_{2}+C_{3}\end{array}$ & $\begin{array}{c}\text { Alpha } \\
C_{0}\end{array}$ \\
\hline $\begin{array}{l}\text { Barclay Trader } \\
\text { CTA }\end{array}$ & 0.063 & 3.92 & $\begin{array}{c}0.00672 \\
(0.61) \\
\end{array}$ & $\begin{array}{c}-0.00116 \\
(-0.13) \\
\end{array}$ & $\begin{array}{c}0.56691 \\
(\mathbf{2 . 3 4}) \\
\end{array}$ & $\begin{array}{c}0.00155 \\
(0.51) \\
\end{array}$ & -- & $\begin{array}{l}-- \\
--\end{array}$ & $\begin{array}{l}-- \\
-- \\
\end{array}$ \\
\hline $\begin{array}{l}\text { Barclay Trader } \\
\text { Discretionary }\end{array}$ & 0.035 & 2.57 & $\begin{array}{c}0.00848 \\
(1.37)\end{array}$ & $\begin{array}{c}0.00021 \\
(0.04)\end{array}$ & $\begin{array}{c}0.27863 \\
(\mathbf{2 . 0 3})\end{array}$ & $\begin{array}{c}0.00041 \\
(0.24)\end{array}$ & -- & $\begin{array}{l}- \\
--\end{array}$ & $\begin{array}{l}- \\
--\end{array}$ \\
\hline $\begin{array}{l}\text { Barclay Trader } \\
\text { Diversified } \\
\end{array}$ & 0.093 & 5.50 & $\begin{array}{c}0.00833 \\
(0.58) \\
\end{array}$ & $\begin{array}{c}-0.00019 \\
(-0.02) \\
\end{array}$ & $\begin{array}{c}0.84184 \\
(\mathbf{2 . 6 4 )} \\
\end{array}$ & $\begin{array}{c}0.00163 \\
(0.41) \\
\end{array}$ & -- & $\begin{array}{l}- \\
-- \\
\end{array}$ & $\begin{array}{l}- \\
-- \\
\end{array}$ \\
\hline $\begin{array}{l}\text { Barclay Trader } \\
\text { Systematic }\end{array}$ & 0.056 & 3.61 & $\begin{array}{c}0.00982 \\
(0.68) \\
\end{array}$ & $\begin{array}{c}-0.00445 \\
(-0.38) \\
\end{array}$ & $\begin{array}{c}0.76539 \\
\mathbf{( - 2 . 4 0 )} \\
\end{array}$ & $\begin{array}{c}0.00240 \\
(0.60) \\
\end{array}$ & -- & $\begin{array}{l}- \\
-- \\
\end{array}$ & $\begin{array}{l}- \\
--\end{array}$ \\
\hline $\begin{array}{l}\text { BTOP 50 } \\
\text { Barclays US } \\
\text { Mgd Fut }\end{array}$ & 0.016 & 1.72 & $\begin{array}{c}0.00609 \\
(0.50)\end{array}$ & $\begin{array}{c}-0.00345 \\
(-0.35)\end{array}$ & $\begin{array}{c}0.46159 \\
(1.70)\end{array}$ & $\begin{array}{c}0.00450 \\
(1.32)\end{array}$ & -- & $\begin{array}{l}-- \\
--\end{array}$ & $\begin{array}{l}-- \\
--\end{array}$ \\
\hline $\begin{array}{l}\text { C/C CTA AW } \\
\text { Discretionary }\end{array}$ & 0.007 & 1.31 & $\begin{array}{c}-0.00467 \\
(-0.53) \\
\end{array}$ & $\begin{array}{c}0.00357 \\
(0.50) \\
\end{array}$ & $\begin{array}{c}0.11555 \\
(0.59) \\
\end{array}$ & $\begin{array}{c}0.00948 \\
\mathbf{( 3 . 8 7 )} \\
\end{array}$ & $11.4 \%$ & $\begin{array}{c}-- \\
0 \% \\
\end{array}$ & $\begin{array}{l}11.4 \% \\
100 \% \\
\end{array}$ \\
\hline $\begin{array}{l}\text { C/C CTA AW } \\
\text { Diversified }\end{array}$ & 0.082 & 4.92 & $\begin{array}{c}0.01282 \\
(0.91) \\
\end{array}$ & $\begin{array}{c}-0.00130 \\
(-0.11) \\
\end{array}$ & $\begin{array}{c}0.83572 \\
\mathbf{( 2 . 6 9 )} \\
\end{array}$ & $\begin{array}{c}0.00155 \\
(0.40) \\
\end{array}$ & -- & $\begin{array}{l}- \\
-- \\
\end{array}$ & $\begin{array}{l}- \\
--\end{array}$ \\
\hline C/C CTA AW & 0.025 & 2.12 & $\begin{array}{c}0.00510 \\
(0.41) \\
\end{array}$ & $\begin{array}{c}-0.00365 \\
(-0.36) \\
\end{array}$ & $\begin{array}{c}0.50320 \\
(1.82) \\
\end{array}$ & $\begin{array}{c}0.00613 \\
(1.76) \\
\end{array}$ & -- & $\begin{array}{l}- \\
--\end{array}$ & $\begin{array}{l}- \\
-- \\
\end{array}$ \\
\hline C/C CTA EW & 0.050 & 3.31 & $\begin{array}{c}0.01144 \\
(0.99) \\
\end{array}$ & $\begin{array}{c}-0.00043 \\
(-0.05) \\
\end{array}$ & $\begin{array}{c}0.57690 \\
(\mathbf{2 . 2 5}) \\
\end{array}$ & $\begin{array}{c}0.00298 \\
(0.92) \\
\end{array}$ & -- & $\begin{array}{l}- \\
-- \\
\end{array}$ & -- \\
\hline $\begin{array}{l}\text { Tuna CTA } \\
\text { /Mgd Fut Avg }\end{array}$ & 0.041 & 2.88 & $\begin{array}{c}0.01022 \\
(0.64) \\
\end{array}$ & $\begin{array}{c}-0.00164 \\
(-0.13) \\
\end{array}$ & $\begin{array}{c}0.72128 \\
\mathbf{( 2 . 0 6 )} \\
\end{array}$ & $\begin{array}{c}0.01096 \\
\mathbf{( 2 . 4 8 )} \\
\end{array}$ & $13.2 \%$ & 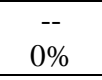 & $\begin{array}{l}13.2 \% \\
100 \% \\
\end{array}$ \\
\hline
\end{tabular}

Notes: 1. There are 132 data points for each regression. 2. Coefficients of the regression results are monthly. 3. The t-values in bold are significant at the 5\% level. 4. The Alpha values are annualized by multiplying the monthly results by a factor of 12.5 . Percentage values below the Alpha results show the percentage out of the total that each component represents. 6 . A "--" for the Alpha results indicates that the result is not statistically supported. 7. Abbreviations: $\mathrm{C} / \mathrm{C}=\mathrm{CASAM} / \mathrm{CISDM}, \mathrm{AW} \& \mathrm{EW}=\mathrm{Asset}$ \& Equal Weighted.

The remaining 7 Indexes show relatively low Adjusted $\mathrm{R}^{2}$ values and low, but above the F-critical value regression statistics. This last result suggests that at least one of the coefficients of the regressions is significant. The results for the 7 Indexes all show the same pattern of statistical significance for only the coefficient, $C_{l}$, the coefficient for the MLM Index or trend following strategy proxy. The Tuna CTA/Managed Futures Average Index also shows a significant t-value for the intercept term, $C_{0}$.

Overall, the results for the first time period regressions suggest several things. First, the majority of the Indexes showed return patterns that are most closely related to those of the trend following proxy Index, i.e. there is some evidence that the majority of the CTA Indexes primarily followed a trend following strategy during the first time period. Second, the effects of the "low" and "high" total return months for the MLM Index did not translate to corresponding major impacts on the individual CTA Indexes tested (all of the coefficients for $C_{2}$ and $C_{3}$ are statistically insignificant). Several of the Indexes showed little to no statistical evidence of any of the coefficients at the 5\% level. These Indexes may follow a different strategy than trend following by Index design, e.g. the CASAM/CISDM CTA Asset Weighted Discretionary Index which does not strictly utilize a trend following strategy. Finally, while the results for this first time period may show some evidence of trend following among the individual CTA Indexes, this does not translate to much strong evidence of Alpha generation nor of corresponding adjustments to Alpha from the binary variables for capturing the effects of large positive and negative return months.

The results for regression (1) for the second time period are shown in Table 3 shown below. It can be seen that for all of the 13 Indexes with complete data for this time period, with the exception of the two CTA Discretionary Indexes one of which shows weak regression fit results and the other which shows practically no support for a good regression fit, the Adjusted $\mathrm{R}^{2}$ values and the overall regression $\mathrm{F}$ statistic are relatively strong; the mean values for both are approximately 0.30 and 18.2 , respectively. 
Table 2: Regression Results For Individual Indexes 2001-2010

\begin{tabular}{|c|c|c|c|c|c|c|c|c|c|}
\hline Index & Adj. $R^{2}$ & $\begin{array}{l}\text { Regr. } \\
\text { F-stat }\end{array}$ & $\begin{array}{c}C_{3} \\
\text { (t-stat) }\end{array}$ & $\begin{array}{c}C_{2} \\
\text { (t-stat) }\end{array}$ & $\begin{array}{c}C_{1} \\
\text { (t-stat) }\end{array}$ & $\begin{array}{c}C_{0} \\
\text { (t-stat) }\end{array}$ & $\begin{array}{c}\text { Alpha } \\
C_{0}+C_{2}+C_{3} \\
\end{array}$ & $\begin{array}{l}\text { Alpha } \\
C_{2}+C_{3}\end{array}$ & $\begin{array}{c}\text { Alpha } \\
C_{0}\end{array}$ \\
\hline $\begin{array}{l}\text { Barclay Trader } \\
\text { CTA }\end{array}$ & 0.271 & 15.72 & $\begin{array}{c}-0.01336 \\
\mathbf{( - 2 . 1 7 )}\end{array}$ & $\begin{array}{c}0.01837 \\
(\mathbf{2 . 3 8})\end{array}$ & $\begin{array}{c}0.19914 \\
(1.29)\end{array}$ & $\begin{array}{c}0.00494 \\
(\mathbf{2 . 5 1 )}\end{array}$ & $12.0 \%$ & $\begin{array}{l}6.0 \% \\
50 \%\end{array}$ & $\begin{array}{l}5.9 \% \\
50 \%\end{array}$ \\
\hline $\begin{array}{l}\text { Barclay Trader } \\
\text { Discretionary }\end{array}$ & 0.038 & 2.56 & $\begin{array}{c}-0.00195 \\
(-0.47)\end{array}$ & $\begin{array}{c}0.01117 \\
(\mathbf{2 . 1 5 )}\end{array}$ & $\begin{array}{c}-0.03236 \\
(-0.31)\end{array}$ & $\begin{array}{c}0.00474 \\
\mathbf{( 3 . 5 6 )}\end{array}$ & $19.1 \%$ & $\begin{array}{c}13.4 \% \\
70 \%\end{array}$ & $\begin{array}{l}5.7 \% \\
30 \%\end{array}$ \\
\hline $\begin{array}{l}\text { Barclay Trader } \\
\text { Diversified }\end{array}$ & 0.302 & 18.20 & $\begin{array}{c}-0.01671 \\
(-1.83)\end{array}$ & $\begin{array}{c}0.02713 \\
(\mathbf{2 . 3 7})\end{array}$ & $\begin{array}{c}0.41702 \\
(1.82)\end{array}$ & $\begin{array}{c}0.00580 \\
(\mathbf{1 . 9 8 )}\end{array}$ & $39.5 \%$ & $\begin{array}{c}32.6 \% \\
82 \%\end{array}$ & $\begin{array}{l}7.0 \% \\
18 \%\end{array}$ \\
\hline $\begin{array}{l}\text { Barclay Trader } \\
\text { Systematic }\end{array}$ & 0.287 & 17.00 & $\begin{array}{c}-0.01565 \\
(-\mathbf{2 . 1 3})\end{array}$ & $\begin{array}{c}0.02009 \\
(\mathbf{2 . 1 8})\end{array}$ & $\begin{array}{c}0.29849 \\
(1.61)\end{array}$ & $\begin{array}{c}0.00491 \\
(\mathbf{2 . 0 8})\end{array}$ & $11.2 \%$ & $\begin{array}{l}5.3 \% \\
48 \%\end{array}$ & $\begin{array}{l}5.9 \% \\
52 \%\end{array}$ \\
\hline $\begin{array}{l}\text { BTOP 50 } \\
\text { Barclays US } \\
\text { Mgd Fut }\end{array}$ & 0.333 & 20.78 & $\begin{array}{c}-0.01947 \\
(-2.74)\end{array}$ & $\begin{array}{c}0.02064 \\
\mathbf{( 2 . 3 2 )}\end{array}$ & $\begin{array}{c}0.28161 \\
(1.58)\end{array}$ & $\begin{array}{c}0.00602 \\
(\mathbf{2 . 6 4 )}\end{array}$ & $8.6 \%$ & $\begin{array}{l}1.4 \% \\
16 \%\end{array}$ & $\begin{array}{l}7.2 \% \\
84 \%\end{array}$ \\
\hline $\begin{array}{l}\text { C/C CTA EW } \\
\text { Discretionary }\end{array}$ & -0.007 & 0.73 & $\begin{array}{c}-0.00694 \\
(-1.03)\end{array}$ & $\begin{array}{c}0.01171 \\
(1.39)\end{array}$ & $\begin{array}{c}-0.20765 \\
(-1.23)\end{array}$ & $\begin{array}{c}0.01023 \\
(\mathbf{4 . 7 6})\end{array}$ & -- & $\begin{array}{l}-- \\
--\end{array}$ & $\begin{array}{l}-- \\
--\end{array}$ \\
\hline $\begin{array}{l}\text { C/C CTA EW } \\
\text { Diversified }\end{array}$ & 0.301 & 18.10 & $\begin{array}{c}-0.0172 \\
(-1.85)\end{array}$ & $\begin{array}{c}0.02610 \\
(\mathbf{2 . 2 4})\end{array}$ & $\begin{array}{c}0.43886 \\
(1.88)\end{array}$ & $\begin{array}{c}0.00790 \\
(\mathbf{2 . 6 5})\end{array}$ & $40.8 \%$ & $\begin{array}{c}31.3 \% \\
77 \%\end{array}$ & $\begin{array}{l}9.5 \% \\
23 \%\end{array}$ \\
\hline $\begin{array}{l}\text { C/C CTA EW } \\
\text { Systematic }\end{array}$ & 0.311 & 18.93 & $\begin{array}{c}-0.0155 \\
(-1.93) \\
\end{array}$ & $\begin{array}{c}0.02018 \\
(\mathbf{2 . 0 1 )} \\
\end{array}$ & $\begin{array}{c}0.41792 \\
(\mathbf{2 . 0 7}) \\
\end{array}$ & $\begin{array}{c}0.00651 \\
(\mathbf{2 . 5 3 )} \\
\end{array}$ & $32.0 \%$ & $\begin{array}{c}24.2 \% \\
76 \% \\
\end{array}$ & $\begin{array}{l}7.8 \% \\
24 \% \\
\end{array}$ \\
\hline C/C CTA EW & 0.299 & 17.89 & $\begin{array}{c}-0.01496 \\
(-\mathbf{2 . 0 3})\end{array}$ & $\begin{array}{c}0.02095 \\
(\mathbf{2 . 2 7})\end{array}$ & $\begin{array}{c}0.31971 \\
(1.73)\end{array}$ & $\begin{array}{c}0.00708 \\
(\mathbf{2 . 9 9 )}\end{array}$ & $15.7 \%$ & $\begin{array}{l}7.2 \% \\
46 \%\end{array}$ & $\begin{array}{l}8.5 \% \\
54 \%\end{array}$ \\
\hline $\begin{array}{l}\text { Eureka CTA } \\
\text { /Mgd Fut HF }\end{array}$ & 0.270 & 15.69 & $\begin{array}{c}-0.01511 \\
(-2.33)\end{array}$ & $\begin{array}{c}0.02216 \\
(\mathbf{2 . 7 2})\end{array}$ & $\begin{array}{c}0.15743 \\
(0.96)\end{array}$ & $\begin{array}{c}0.01004 \\
\mathbf{( 4 . 8 2 )}\end{array}$ & $20.5 \%$ & $\begin{array}{l}8.5 \% \\
41 \%\end{array}$ & $\begin{array}{c}12.0 \% \\
59 \%\end{array}$ \\
\hline $\begin{array}{l}\text { Eureka CTA } \\
\text { FoF }\end{array}$ & 0.301 & 18.09 & $\begin{array}{c}-0.01793 \\
\mathbf{( - 2 . 6 6 )}\end{array}$ & $\begin{array}{c}0.01990 \\
(\mathbf{2 . 3 6})\end{array}$ & $\begin{array}{c}0.21791 \\
(1.29)\end{array}$ & $\begin{array}{c}0.00663 \\
(\mathbf{3 . 0 6})\end{array}$ & $10.3 \%$ & $\begin{array}{l}2.4 \% \\
23 \%\end{array}$ & $\begin{array}{l}8.0 \% \\
77 \%\end{array}$ \\
\hline $\begin{array}{l}\text { Eureka Global } \\
\text { CTA FoF }\end{array}$ & 0.306 & 18.47 & $\begin{array}{c}-0.01868 \\
\mathbf{( - 2 . 7 3 )}\end{array}$ & $\begin{array}{c}0.01965 \\
(\mathbf{2 . 2 9})\end{array}$ & $\begin{array}{c}0.22817 \\
(1.33)\end{array}$ & $\begin{array}{c}0.00642 \\
(\mathbf{2 . 9 2})\end{array}$ & $8.9 \%$ & $\begin{array}{l}1.2 \% \\
13 \%\end{array}$ & $\begin{array}{l}7.7 \% \\
87 \%\end{array}$ \\
\hline Newedge CTA & 0.333 & 20.76 & $\begin{array}{c}-0.02131 \\
(-2.96)\end{array}$ & $\begin{array}{c}0.01884 \\
(\mathbf{2 . 0 8})\end{array}$ & $\begin{array}{c}0.28282 \\
(1.56)\end{array}$ & $\begin{array}{c}0.00682 \\
(\mathbf{2 . 9 5})\end{array}$ & $5.2 \%$ & $\begin{array}{l}-3.0 \% \\
-57 \%\end{array}$ & $\begin{array}{l}8.2 \% \\
157 \%\end{array}$ \\
\hline
\end{tabular}

Notes: 1. There are 120 data points for each regression. 2. Coefficients of the regression results are monthly. 3. The t-values in bold are significant at the 5\% level. 4. The Alpha values are annualized by multiplying the monthly results by a factor of 12.5 . Percentage values below the Alpha results show the percentage out of the total that each component represents. 6 . A "--" for the Alpha results indicates that the result is not statistically supported. 7. Abbreviations: $\mathrm{C} / \mathrm{C}=\mathrm{CASAM} / \mathrm{CISDM}, \mathrm{EW}=\mathrm{Equal}$ Weighted, HF $=$ Hedge Fund, FoF $=$ Fund of Funds, Eureka = Eurekahedge.

Of the 13 CTA Indexes, 8 Indexes, about $63 \%$ of the total, show the same pattern of statistical significance at the 5\% level for the coefficients $C_{3}, C_{2}$, and $C_{0}$, but not for $C_{1}$, the coefficient for the MLM Index or trend following strategy proxy. Regression results for the remaining 3 Indexes, excepting the 2 Discretionary Indexes and the previously described 8 Indexes, are divided as follows: the 2 Diversified Indexes showed statistical significance for only coefficients $C_{2}$ and $C_{0}$. The CASAM/CISDM CTA Equal Weighted Systematic Index shows the same pattern as the Diversified Indexes with the exception that this is the only Index for which the MLM Index total return coefficient, $C_{l}$, is also statistically significant. In summary, the regression results support the general model fit and also show significant impact from the "high" and "low" month total returns of the MLM Index.

The contribution to the Total Alpha calculation from the annualized sum of the coefficient for $C_{3}$ and $C_{2}$ exceeds $40 \%$ for 8 of the Indexes (62\%). Four of this set of 8 Indexes, which include 1 Discretionary Index, 2 Diversified Indexes and 1 Systematic Index, showed unusually high Total Alpha contribution from the coefficients for $C_{3}$ and $C_{2}, 70 \%$ to $80 \%$ of the total; this is due to the lack of a statistically significant coefficient for $C_{3}$ which is negative in all cases and acts to counter the positive effects of $C_{2}$. The Newedge CTA Index was the only Index for which the coefficient from the "low" return months outweighed the contribution from the coefficient for the "high" 
return months. The CTA Indexes utilizing the Fund of Funds approach along with the BTOP 50 Barclays US Managed Futures Index had the lowest annualized contribution from these two coefficients with a range of percentage of the Total Alpha between 13\% and 23\%. This makes sense for the Fund of Funds Indexes because this investment strategy will be less likely to be impacted by "high" and "low" return months because of the diversification across funds that utilize both non-trend following strategies as well as trend following strategies. Finally, one of the Discretionary Indexes showed practically no regression statistics to support the Alpha calculations.

Overall, the results for the second time period regressions suggest several things. First, all but 1 Index provided regression results supportive of the impact of the "high" and "low" total return months for the MLM Index, i.e. the large return months for the trend following proxy Index did translate into the Total Alpha adjustments. Indeed, the results suggest that on average, approximately 50\% of the Total Alpha values are associated with these large return months (with the positive coefficients almost universally outweighing the negative coefficients for an overall positive contribution to Total Alpha) while the other 50\%, on average, originates with the traditional Alpha value, $C_{0}$. This suggests that while the coefficient for the monthly total returns of the MLM Index trend following proxy is generally not statistically significant, the long/short strategies and other, more complex strategies, may have improved quite possibly because of increased commodity demand and major economic signals may have made trends and trend reversals less difficult to forecast.

The increased demand for certain commodities from countries such as China, India, Brazil, and Russia as well as major economic turmoil during time period two is well known. This may account for some of the very different results for time period one versus time period 2. Finally, another possible explanation for the results is that the underlying CTA investment strategies may have evolved in complexity over time to include increased use of options and other derivatives among other aspects. The underlying reasons for the difference is investigated further in the following paragraphs.

\section{Further Analyses}

A logical first step is to examine the distribution of total returns of the MLM Index because it is central to the analysis. Histograms for the monthly total return distributions of the MLM Index, the proxy Index for a trend following strategy, are shown in Figures 1 and 2 for the first and second time period, respectively. Descriptive statistics for the MLM Index for both time periods are shown in Table 4 below the histograms. It can be seen from the descriptive statistics shown in Table 4 that the annualized mean return was higher in time period 1 than 2 and the annualized volatility was lower in time period 1 than 2 . Also, the skewness of the total return distribution was negative, longer left-hand tail, for time period 1 and positive for time period 2. For both time periods the kurtosis values, though leptokurtic, are also relatively close in value to 3 which is the kurtosis value for a normal distribution. During time period 1 there were 2 negative return months for the MLM Index which exceeded -3 standard deviations from the mean and 1 positive return months which exceeded +3 standard deviations from the mean. For time period 2, there were 2 negative and 2 positive return months which exceeded the $+/-3$ standard deviations from the mean region. The MLM Index monthly total returns appear close in shape to the normal distribution though the shape is slightly skewed to the left in time period 1 and to the right in time period 2. 


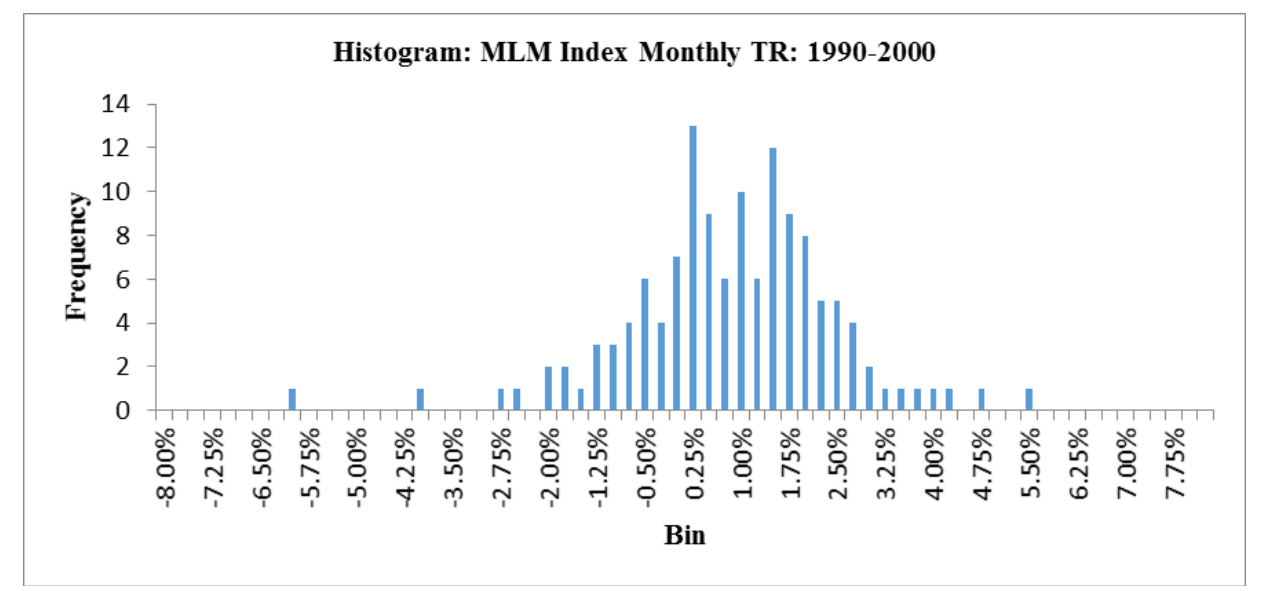

Figure 1: Histogram Of MLM Index Monthly Total Returns: 1990-2000

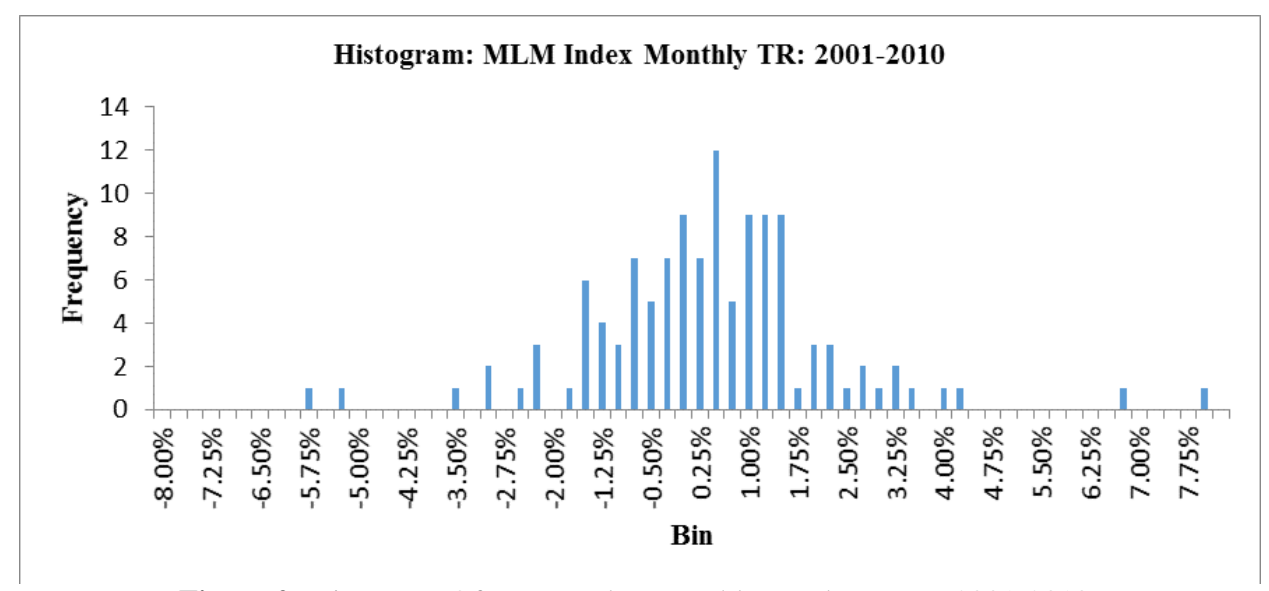

Figure 2: Histogram Of MLM Index Monthly Total Returns: 2001-2010

Table 3: Descriptive Statistics For The MLM Index Total Returns

\begin{tabular}{cccccc}
\hline \multicolumn{1}{c}{ Time Period } & No. Months & $\begin{array}{c}\text { Annualized } \\
\text { Mean Return }\end{array}$ & Ann. Volatility & Skew & Kurt \\
\hline Feb-90 to Dec-00 & 131 & $8.61 \%$ & $5.57 \%$ & -0.55 & 2.48 \\
Jan-01 to Dec-10 & 120 & $3.17 \%$ & $6.45 \%$ & 0.33 & 3.54 \\
\hline Notes:
\end{tabular}

Notes: The Annualized Mean Return and Annualized Volatility values were calculated by multiplying monthly values by a factor of 12 and the square root of 12 , respectively.

During the first time period there were 18 "high" return months and only 12 "low" return months for the MLM Index. However, during the second time period, this pattern switched to 11 "high" return months and 20 "low" return months. These are simple counting statistics and it is evident from the regression results that during time period 2, although there are fewer "high" return months than "low" return months, the impact of the "high" return months to the Alpha adjustment values for the Indexes are overwhelmingly greater than those of the more numerous, though less impactful, "low" return months. It may be helpful here to remember the definition of "high" and "low" return months. Both are outside the region of $+/-1$ standard deviation from the MLM Index's monthly total return value; because of the proximity of the overall shape of the MLM Index's distribution to the normal distribution during both time periods, prior research by the author resulted in selecting this region as reasonable for separating the "normal" return months from the larger negative and positive return months.

These results are supported by other analyses such as ranking the monthly return data on the MLM Index returns with the individual CTA indexes with full data for the time periods. Overall, for both time periods but less so in time period one, this analysis shows that for the majority of months the individual CTA Indexes return patterns 
were generally similar to those of the top and bottom $10 \%$ of monthly returns of the MLM Index, especially for the large positive return months. This is somewhat less true for the large negative return months where more variation in individual CTA Index returns is indicated. These results suggest that CTAs may be somewhat superior at predicting, ex ante, large positive gains in the positions they make than in predicting large losses to their positions. Perhaps this might be explained by the nature of trend following itself; it may possibly be an inherently more conducive strategy at capturing signals of continuing positive trends in positions than signaling large reversals as suggested previously.

Another supporting analysis includes calculations of correlation statistics of the monthly return data. The Pearson correlation statistic of the equal weighted portfolio of all of the 24 Indexes with monthly return data available with the MLM Index for the first time period is 0.28 , while for the second time period it is nearly double that value at 0.52 . For the first time period, the correlations between individual CTA Indexes is quite high with an average value of approximately 0.9 with the exception of the two Discretionary CTA Indexes (which do not necessarily follow a trend following strategy) and the Newedge Commodity Trading Index. For these three indexes, the correlations with the other Indexes was generally less than 0.5 . For the second time period, the correlations between CTA and three Macro hedge fund Indexes remained high with the exception of the Macro hedge fund Indexes, the three Discretionary CTA Indexes available for this time period, and the Newedge Commodity Trading Index. The correlations between these Indexes and the other CTA Indexes were generally less than approximately 0.4. Correlations between the individual CTA and the three Macro hedge fund Indexes with the MLM Index averaged about 0.25 for the first time period and about 0.50 for the second time period, with the same low correlation Indexes excepted for both time periods as indicated for the between CTA Index correlations.

It is worth noting two things: 1) the average correlation between the individual CTA Indexes and the MLM Index for the first time period is 0.32 (excepting the two Discretionary Indexes with data for this time period and the Newedge Commodity Trading Index), and for the second time period the average is 0.52 (excepting the three Discretionary Indexes, two out of three of the Macro hedge fund Indexes - the HFRX Macro: Systematic Diversified CTA Index was included - and the Newedge Commodity Trading Index), and 2) the percentage of CTA Indexes with a higher correlation or about the same with the MLM Index during the first time period is $12 \%$, average correlation 0.20 , while the remaining $88 \%$ of the CTA Indexes showed higher correlation values with the MLM Index for the second time period than the first with an average correlation of 0.49 (with the exception of the three Discretionary funds and the three Macro hedge funds). In summary, the correlations indicate several points: 1) the monthly returns of the CTA Indexes are strongly related to each other with the exceptions noted previously, 2) the monthly return correlations of the majority of the CTA Indexes with the MLM Index is more than twice as high on average in the second time period than the first.

Another question that deserves investigation is how the markets traded, the underlying commodities markets, performed during both time periods and how this may have affected the performance of the CTA Indexes and the trend following Index proxy. Two composite commodity Indexes (replicating Indexes) were created using separate underlying commodity components and are long only. The Indexes, their components, and weightings are as follows: Index $1-15 \%$ Currency, 15\% Fixed Income, 70\% spread between individual contracts of Agriculture, Livestock, Precious Metals, Industrial Metals, and refined and unrefined Oil and Gasoline; Index $2-15 \%$ Currency, 15\% Fixed Income, 70\% spread between aggregate commodity sectors comprised of Agriculture, Livestock, Energy, Industrial Metal, and Precious Metal.

Correlation matrices for the monthly returns of the two composite commodity Indexes with the MLM Index, the equal weighted Portfolio of the CTA Indexes, and the S\&P 500 Total Return Index are shown below in Tables 5 and 6: 
Table 4: Index Correlations: Feb 1990 Through Dec 2000

\begin{tabular}{lccccc}
\hline & Index 1 & Index 2 & MLM Index & Portfolio Index & S\&P500 TR \\
\hline Index 1 & 1 & & & & \\
Index 2 & 0.88 & 1 & & & \\
MLM Index & -0.07 & 0.03 & 0.28 & 1 & \\
Portfolio Index & 0.08 & 0.17 & -0.29 & -0.09 & 1 \\
S\&P500 TR & -0.03 & -0.02 & -0.29 & \\
\hline
\end{tabular}

Table 5: Index Correlations: Jan 2001 through Dec 2010

\begin{tabular}{lccccc}
\hline & Index 1 & Index 2 & MLM Index & Portfolio Index & S\&P500 TR \\
\hline Index 1 & 1 & & & & \\
Index 2 & 0.93 & 1 & & & \\
MLM Index & -0.08 & -0.02 & 1 & 1 & \\
Portfolio Index & 0.33 & 0.37 & 0.52 & -0.08 & 1 \\
S\&P500 TR & 0.35 & 0.41 & -0.30 & \\
\hline
\end{tabular}

For time period one and two the correlation between Index 1 and 2 remains high at approximately 0.9 . The correlation between the Portfolio Index and the MLM Index increases from time period one to time period two nearly two times. As expected, for time period one the correlation between the composite commodity Indexes, the MLM Index, the Portfolio Index, and the S\&P 500 Index are all near zero to negative. However, for time period two, the correlation between the S\&P 500 Index and the composite commodity Indexes is positive and moderately high. This is likely due to the influence of the currency and fixed income components of the composite Indexes. Also, for time period two, the correlations between the Portfolio Index and the composite commodity Indexes increases significantly.

Statistics for the composite commodity Indexes 1 and 2, the MLM Index and the Portfolio of CTA Indexes are shown below in Table 7 and the geometric growth of a $\$ 100$ initial investment are plotted for both time periods in Figures 3 and 4 in an upcoming section:

Table 6: Descriptive Statistics For Indexes 1 \& 2, MLM Index, And Portfolio Index

\begin{tabular}{ccccccccc}
\hline \multirow{2}{*}{ Index } & Time Period & $\begin{array}{c}\text { No. } \\
\text { Months }\end{array}$ & $\begin{array}{c}\text { Ann. } \\
\text { Mean Ret. }\end{array}$ & $\begin{array}{c}\text { Ann. } \\
\text { Volatility }\end{array}$ & Skew & Kurt & Sharpe & $\begin{array}{c}\text { Geom. } \\
\text { Growth }\end{array}$ \\
\hline Index 1 & Feb-90 to Dec-00 & 131 & $6.21 \%$ & $6.71 \%$ & 0.31 & 1.34 & 0.18 & $91.9 \%$ \\
\hline & Jan-01 to Dec-10 & 120 & $8.97 \%$ & $9.93 \%$ & -0.95 & 3.89 & 0.65 & $132.8 \%$ \\
\hline \multirow{2}{*}{ Index 2 } & Feb-90 to Dec-00 & 131 & $5.66 \%$ & $5.86 \%$ & 0.08 & 1.05 & 0.11 & $81.9 \%$ \\
& Jan-01 to Dec-10 & 120 & $8.34 \%$ & $9.16 \%$ & -1.17 & 4.77 & 0.64 & $120.1 \%$ \\
\hline MLM & Feb-90 to Dec-00 & 131 & $8.61 \%$ & $5.57 \%$ & -0.55 & 2.48 & 0.65 & $150.9 \%$ \\
Index & Jan-01 to Dec-10 & 120 & $3.17 \%$ & $6.45 \%$ & 0.33 & 3.54 & -0.28 & $34.4 \%$ \\
\hline Portfolio & Feb-90 to Dec-00 & 131 & $10.99 \%$ & $9.59 \%$ & 0.61 & 0.67 & 0.62 & $214.4 \%$ \\
Index & Jan-01 to Dec-10 & 120 & $8.39 \%$ & $7.36 \%$ & 0.12 & -0.16 & 0.46 & $124.7 \%$ \\
\hline
\end{tabular}

Notes: 1. Mean Monthly Return and Standard Deviation values were annualized by multiplying by a factor of 12 and the square root of 12, respectively. 2. Sharpe Ratios were calculated using average risk-free rates of 5\% and $2.5 \%$ for time period 1 and 2 , respectively. 3. Geometric Growth values were calculated by computing the total return an Index earned on an initial investment of $\$ 100$.

For composite commodity Indexes 1 and 2, it can be seen that the performance statistics are higher for time period 2 than for time period 1 despite the shorter length of time for time period 2 and the negative skewness and the kurtosis tending toward to a normal return distribution shape. The volatility is also higher for time period 2 than for time period 1 for these Indexes. For the MLM Index and the Portfolio Index, however, the performance statistics are reversed; time period one shows greater performance than time period 2. The MLM Index shows negative skewness and nearly normal kurtosis for time period one while for time period two it shows slightly positive skewness and again nearly normal kurtosis. These statistics combined with the poor Sharpe ratios and very low geometric growth values are particularly important because they indicate that the trend following strategy proxy did not necessarily perform well during time period 2 but the Portfolio of CTA Indexes performed quite well even during the economic crisis of 2008. 
Although the trend following strategy Index proxy, the MLM Index, did underperform the Portfolio of CTA Indexes during time period 1 also, the difference was not as drastic as in time period 2. This may indicate a previous research result by Martin (1999) that tactical diversification across hedge fund style indexes is much more beneficial than picking individual hedge fund managers; in this context, it this may indicate that diversification across a range of CTA investment style Indexes is more beneficial to investors than investing with a single or smaller group of CTA Indexes or funds with similar investment style.

The geometric growth of a $\$ 100$ initial investment is shown graphically below in Figures 3 and 4 for Indexes 1 and 2, the MLM Index, and the Portfolio of CTA Indexes for both time periods:

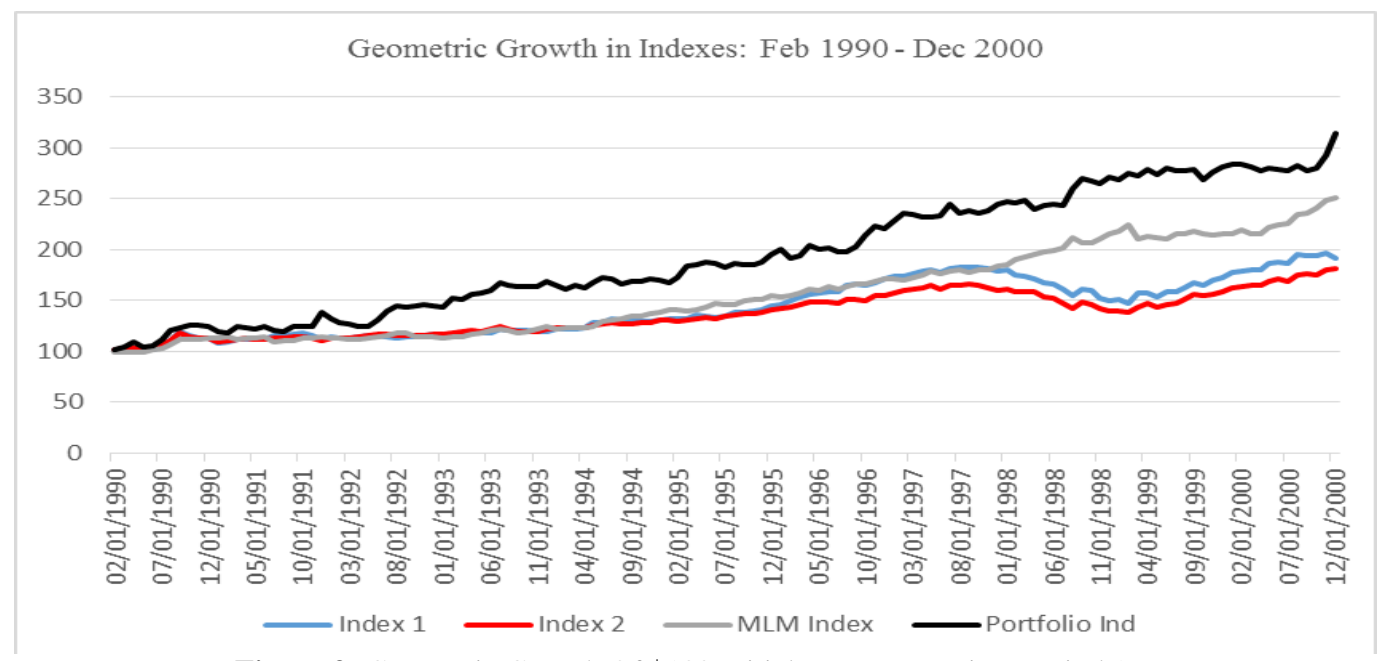

Figure 3: Geometric Growth Of $\$ 100$ Initial Investment Time Period 1

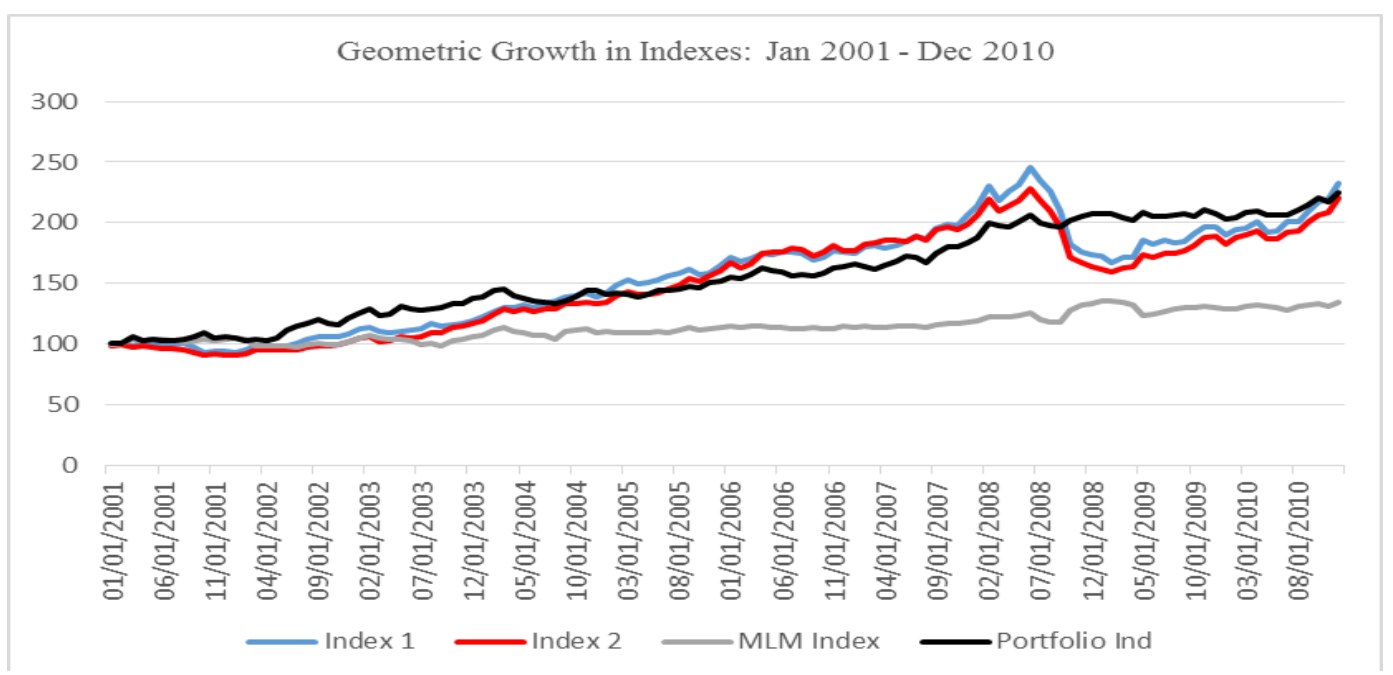

Figure 4: Geometric Growth Of \$100 Initial Investment Time Period 2

For time period 1, Figure 3 clearly shows that while the underlying composite commodity Indexes suffered losses (to a long position) during the August 1998 crisis and its aftermath, the MLM Index and the Portfolio Index both performed well likely due to their ability to take long and short positions as well as employ various derivatives. It can also be seen that during the beginning of the large decline of the US equities markets the commodities and CTA sectors remained largely unaffected. For time period 2, Figure 4 clearly shows the large increases in a long position to commodities up to the 2008 crisis and the continuation of growth beyond the crisis which is likely explained by the large demand for certain commodities from China, Brazil, Russia, and India for example. This momentum in growth in demand for the underlying commodities is reflected in the Portfolio of CTA Indexes growth 
but not in the MLM Index trend following strategy proxy. The lack of growth in the MLM Index strategy may help explain the regression results: during time period 1, the underlying composite commodity Indexes track the MLM Index closely until about the beginning of 1998 when the composite commodity Indexes start returning negative values to a long position but the MLM Index returns continue to be positive. This could have accounted for the low Adjusted $\mathrm{R}^{2}$ values and the significance of only the MLM Index return coefficients for most of the individual CTA Indexes because, like the MLM Index, the individual CTA Index component funds can also take short positions.

During time period 2, we see that the MLM Index returns diverge from the returns of the underlying composite commodity Indexes' long positions, especially during the negative returns months for the commodities Indexes during the 2008 crisis when the MLM Index returns were positive for much of that period; short positions are the most obvious clue. The regression results show that for most of the individual CTA Indexes the MLM Index returns coefficient is not significant while the Alpha value for return to skill, $C_{0}$, and the Alpha adjustment coefficients for large positive and negative MLM Index returns are generally all statistically significant. The regression Adjusted $\mathrm{R}^{2}$ values are also significantly higher for most of the individual CTA Indexes.

In summary, the combined results presented above provide possible underlying reasons for the regression results presented earlier. During time period 1, the divergence of the long only underlying composite commodity Indexes and the MLM Index (and the Portfolio of CTA Indexes) for the time period beginning approximately at the beginning of 1998 and lasting through the first quarter of 1999 suggests that the success of a trend following strategy depended to some degree on the ability to short the underlying commodities markets and other markets traded. The MLM Index can and does short certain commodities, currencies, and fixed income markets. The general pattern of the significance of only the MLM Index monthly total return coefficient for most of the individual CTA Indexes may be attributed to the long/short positions of the MLM Index; the "high" positive and "low" negative returns months did not appear to be of much impact for the first time period. The low Adjusted $\mathrm{R}^{2}$ values of the regressions for time period 1 may be a result of different mixes of asset markets traded for the individual CTA Indexes than the MLM Index which trades in certain commodities, currencies, and fixed income markets.

For time period 2, Figure 4 shows that the underlying composite commodity Indexes exhibited a large period of growth until the crisis of 2008 and lasting into the first quarter of 2009 when these markets again rebounded until the end of the data sample; as suggested previously, demand from emerging economies, China in particular, may have fueled the growth in certain commodities during this period. As shown in Tables 5 and 6 it can be seen that the correlations between the MLM Index and the composite commodity Indexes 1 and 2 remained quite low, while the correlations of these Indexes with the Portfolio of CTA Indexes increased dramatically from time period one to time period 2. In addition, the correlation between the MLM Index and the Portfolio of CTA Indexes nearly doubled from time period 1 to 2 . However, Figure 4 shows that the Portfolio of CTA Indexes increased continuously throughout time period 2, even when the composite commodity Indexes suffered losses during the crisis, while the MLM Index increased in value relatively little. These results suggest that the returns to the MLM Index should not be a significant factor, but that the large gains and losses in the MLM Index may play a large role; this is what the regression results for time period 2 show in general for most of the individual CTA Indexes; the Alpha value for "return to skill", $C_{0}$, and the Alpha adjustment values for large positive and negative returns, $C_{2}$ and $C_{3}$, are nearly all significant. Sorting monthly returns on the Portfolio of CTA Indexes shows that the large positive returns for the Portfolio Index are associated with large gains or losses for the composite commodity Indexes and smaller positive returns for the MLM Index. The same general pattern also holds true for the large negative losses of the Portfolio Index; the composite commodity Indexes returns are large positive and negative in magnitude while the MLM Index returns are smaller in magnitude. So, while the Portfolio of CTA Indexes returns may follow the general pattern of the returns of the MLM Index, they are larger in magnitude. This suggests a plausible reason for the much larger growth in the Portfolio of CTA Indexes than the MLM Index.

Ranking the monthly returns on composite commodity Index 1 shows that the bottom $10 \%$ of monthly returns for Index 1 are associated with generally positive monthly returns for the MLM Index and to a lesser degree the Portfolio of CTA Indexes for time period 1; of note is that for the months leading up to, including, and following August 1998 both the MLM Index and the Portfolio Index generally show positive returns. This is less true for both Indexes for the bottom 10\% of Index 1 monthly returns for time period 2 where large losses are associated with large losses in Index 1, especially in the year 2008. For the top 10\% of monthly returns for Index 1 for time period 
1, the MLM Index and the Portfolio Index generally show positive returns. For the second time period this holds more strongly with most of the large positive returns occurring pre-fall 2008 with a few in 2010.

\section{CONCLUSIONS}

This research has shown evidence of several important contributing results to the literature on CTAs. It introduces a model designed to capture the effects of "high" and "low" return months for a trend following proxy Index on the return patterns and performance of a sample of CTA Indexes taken from a larger set of 24 CTA Indexes. In combination with the regression model it also offers a unique Alpha adjustment designed to include not only the traditional Alpha, but also a reward/penalty system linked to the performance of the trend following proxy Index. In this way, the previously documented dominant trading strategy for most CTAs, trend following, is investigated over a 21 year total time period which includes several large economic and market upheavals. However, it must be pointed out that not all CTA Indexes are designed to track only a trend following strategy; trend following may be a component, but only selectively. The results of this research provide evidence of this for several of the Indexes.

Results show that the total sample contained a break around the period of 2000 to 2001, consequently the sample was divided into two time periods. Regression results for the first time period, January 1990 through December 2000, show evidence of at least some association of the returns of the trend following proxy to those of the individual CTA Indexes; however, most of the Indexes showed little to no statistical support for much traditional or adjusted Total Alpha generation. For the second time period, the regression results are much stronger and vastly different. For most all of the CTA Indexes, results show that almost none of the Indexes had a statistically significant association with the monthly total returns of the trend following Index. Instead, generally all of the Indexes showed the impact of the "high" and "low" monthly returns of the trend following proxy Index such that they generated significant traditional Alpha and required at least some Alpha adjustment for the impact of the "high"

and "low" return months for the Index proxy. The Alpha adjustments were overwhelmingly positive and, on average, accounted for approximately 50\% of the Total Alpha generation of the individual CTA Indexes; again, Total Alpha is the traditional Alpha plus or minus a reward or penalty for association with the larger positive and negative return patterns of the trend following proxy Index. The key is to investigate the relationship between a trend following proxy Index's return patterns and the return patterns of individual CTA Indexes to see which Indexes are most closely related to a trend following strategy and what the association is of the larger positive and negative returns to the proxy Index with those of the individual Indexes.

Additional investigations into the underlying reasons for the differences in the regression results for time period 1 and 2 were conducted. Generally, the overall reasons for the differences varied by analysis type but all support a common theme; time period 2 had much greater relationships to the larger returns of the trend following proxy Index than in time period 1. This could be because of several reasons. First, the second time period includes the effects of the "Great Recession" and analyses show that this time period presented opportunities for CTAs to generate generally larger returns during the crisis and in the months following it. Second, demand in the underlying commodities markets increased significantly during time period 2 as compared to time period 1 . This may have made trending periods and trend reversal signals more conducive to predict ex ante for many CTA funds. Also, the growth of the trend following proxy Index during time period 2 was much less than in time period 1. This and patterns of growth in replicating Indexes of the underlying commodities markets and a portfolio of all of the CTA Indexes reporting returns during a given month, indicate that the portfolio of CTA Indexes with a mix of differing investment strategies is the better performing investment rather than investing in one or several individual Indexes following the same investment strategy; additionally, the underlying commodities markets' replicating Indexes showed significantly larger growth in time period 2 over time period 1 even though time period 1 includes an additional year of data. This supports the growth in demand in the underlying commodities markets. While some individual CTA Indexes have highly correlated return values with each other, others do not and this is likely due to the trading strategy style or asset class the Index is designed to track. Finally, the underlying investment strategies of the CTA funds and CTA-like funds evolved over time to become more complex in strategy and mix of options and other derivatives. Indeed, the line is blurring between investment vehicles among Commodity Trading Advisors (CTAs), Managed Futures funds, Hedge Funds and other investment vehicles. 
Future research is being considered using the Dynamic Conditional Correlation methods of Engle (2000). This will require the use of daily data so model specification changes may be necessary. A large problem with working with CTAs and other alternative investment vehicles is that at this time most of the Index data is available only on a monthly basis due to the fact that the component funds report to the data vendors at best on a monthly basis while some report on a quarterly basis. More specialized methods such as those proposed by Engle (2000) require higher frequency data than monthly data to be an improvement over existing methods. Some data providers have just recently begun to provide daily data for their Indexes, e.g. Barclayhedge. Daily data for individual funds may not be forthcoming, in fact it may not even be reasonable for funds that hold illiquid assets or assets that are difficult to value. However, at least the industry is making moves in this direction for some of their Indexes.

\section{AUTHOR INFORMATION}

Scott Mackey, Ph.D., is an Associate Professor of Finance at the Mario J. Gabelli School of Business at Roger Williams University. He has over 14 years of academic experience in addition to 7 years of consulting experience. Scott completed his doctoral degree at the University of Massachusetts while researching Hedge Funds. His main teaching endeavors include International Finance and Financial Derivatives while his research interests focus mainly on the area of Alternative Investments. He has published articles in the Journal of Alternative Investments and the Journal of Wealth Management among others. Scott Mackey, Ph.D., Associate Professor of Finance, Gabelli School of Business, Roger Williams University, One Old Ferry Road, Bristol, RI 02809-2921 USA. Email: $\underline{\text { smackey@rwu.edu }}$

\section{ACKNOWLEDGEMENTS}

The author would like to thank Dr. Hossein Kazemi and Dr. Thomas Schneeweis of the University of Massachusetts, Amherst for their generous donation of the database and continuing support.

\section{REFERENCES}

1. Baesel, J. B., Gonzalez-Heres, J. F., Chen, P., and Shin, S. S. (2012). The effect of S\&P 500 correlation on hedge fund alpha. The Journal of Wealth Management, 14(4), 93-104.

2. Engle, R. F. (2000). Dynamic conditional correlation - a simple class of multivariate GARCH models. Working Paper.

3. Fung, W., and, Hsieh, D. A. (1997). The information content of performance track records: investment style and survivorship bias in the historical returns of commodity trading advisors. Journal of Portfolio Management, 24(1), 30-41.

4. Martin, G. (1999). Making sense of hedge fund returns: what matters and what doesn't. Derivatives Strategy.

5. Schneeweis, T., and, Spurgin, R. (1996). Quantitative analysis of hedge fund and managed futures return and risk characteristics. Working Paper, Center for International Securities and Derivatives Markets (CISDM).

6. Spurgin, R. (1999). Some thoughts on the sources of return to managed futures. Working Paper, Clark University/CISDM. 
APPENDIX A

Table 1: CTA/Managed Futures \& Hedge Fund Index Descriptive Statistics

\begin{tabular}{|c|c|c|c|c|c|c|c|}
\hline Index & Start Date & End Date & $\begin{array}{l}\text { No. Data } \\
\text { Pts. }\end{array}$ & $\begin{array}{c}\text { Mean Mo. } \\
\text { Return }\end{array}$ & $\begin{array}{c}\text { Stdev. of } \\
\text { Mo. Return }\end{array}$ & Skew & Kurt \\
\hline BAIF HF CTA MGD FUT & $2 / 28 / 2005$ & $12 / 31 / 2010$ & 71 & $0.71 \%$ & $2.83 \%$ & -0.02 & -0.87 \\
\hline \multirow[t]{3}{*}{ Barclay Trader CTA } & $1 / 31 / 1990$ & $12 / 31 / 2010$ & 252 & $0.56 \%$ & $2.40 \%$ & 0.41 & 0.69 \\
\hline & $1 / 31 / 1990$ & $12 / 31 / 2000$ & 132 & $0.61 \%$ & $2.69 \%$ & 0.48 & 0.54 \\
\hline & $1 / 31 / 2001$ & $12 / 31 / 2010$ & 120 & $0.49 \%$ & $2.06 \%$ & 0.15 & 0.23 \\
\hline \multirow[t]{3}{*}{ Barclay Trader Discretionary } & $1 / 31 / 1990$ & $12 / 31 / 2010$ & 252 & $0.42 \%$ & $1.37 \%$ & 1.03 & 4.47 \\
\hline & $1 / 31 / 1990$ & $12 / 31 / 2000$ & 132 & $0.32 \%$ & $1.49 \%$ & 1.32 & 5.86 \\
\hline & $1 / 31 / 2001$ & $12 / 31 / 2010$ & 120 & $0.54 \%$ & $1.21 \%$ & 0.58 & 1.11 \\
\hline \multirow[t]{3}{*}{ Barclay Trader Diversified } & $1 / 31 / 1990$ & $12 / 31 / 2010$ & 252 & $0.76 \%$ & $3.37 \%$ & 0.39 & 0.26 \\
\hline & $1 / 31 / 1990$ & $12 / 31 / 2000$ & 132 & $0.85 \%$ & $3.59 \%$ & 0.48 & 0.19 \\
\hline & $1 / 31 / 2001$ & $12 / 31 / 2010$ & 120 & $0.66 \%$ & $3.12 \%$ & 0.20 & 0.22 \\
\hline \multirow[t]{3}{*}{ Barclay Trader Systematic } & $1 / 31 / 1990$ & $12 / 31 / 2010$ & 252 & $0.67 \%$ & $3.08 \%$ & 0.66 & 1.62 \\
\hline & $1 / 31 / 1990$ & $12 / 31 / 2000$ & 132 & $0.83 \%$ & $3.52 \%$ & 0.75 & 1.34 \\
\hline & $1 / 31 / 2001$ & $12 / 31 / 2010$ & 120 & $0.49 \%$ & $2.49 \%$ & 0.12 & 0.16 \\
\hline BTOP 50 Barclays US Mgd & $1 / 31 / 1990$ & $12 / 31 / 2010$ & 252 & $0.67 \%$ & $2.73 \%$ & 0.42 & 0.78 \\
\hline \multirow[t]{2}{*}{ Fut } & $1 / 31 / 1990$ & $12 / 31 / 2000$ & 132 & $0.79 \%$ & $2.93 \%$ & 0.62 & 0.82 \\
\hline & $1 / 31 / 2001$ & $12 / 31 / 2010$ & 120 & $0.54 \%$ & $2.49 \%$ & -0.01 & 0.28 \\
\hline \multirow[t]{3}{*}{ C/C CTA AW Discretionary } & $1 / 31 / 1990$ & $2 / 28 / 2010$ & 242 & $0.92 \%$ & $1.99 \%$ & 0.87 & 1.52 \\
\hline & $1 / 31 / 1990$ & $12 / 31 / 2000$ & 132 & $1.04 \%$ & $2.09 \%$ & 0.62 & 1.01 \\
\hline & $1 / 31 / 2001$ & $2 / 28 / 2010$ & 110 & $0.77 \%$ & $1.85 \%$ & 1.27 & 2.66 \\
\hline \multirow[t]{3}{*}{ C/C CTA AW Diversified } & $1 / 31 / 1990$ & $2 / 28 / 2010$ & 242 & $0.74 \%$ & $3.12 \%$ & 0.43 & 0.60 \\
\hline & $1 / 31 / 1990$ & $12 / 31 / 2000$ & 132 & $0.86 \%$ & $3.48 \%$ & 0.51 & 0.60 \\
\hline & $1 / 31 / 2001$ & $2 / 28 / 2010$ & 110 & $0.59 \%$ & $2.62 \%$ & 0.03 & -0.71 \\
\hline \multirow[t]{3}{*}{ C/C CTA AW } & $1 / 31 / 1990$ & $10 / 31 / 2010$ & 250 & $0.83 \%$ & $2.72 \%$ & 0.63 & 1.97 \\
\hline & $1 / 31 / 1990$ & $12 / 31 / 2000$ & 132 & $0.98 \%$ & $3.00 \%$ & 0.85 & 2.44 \\
\hline & $1 / 31 / 2001$ & $10 / 31 / 2010$ & 118 & $0.66 \%$ & $2.35 \%$ & -0.02 & -0.70 \\
\hline C/C CTA EW Discretionary & $1 / 31 / 2001$ & $12 / 31 / 2010$ & 120 & $0.96 \%$ & $1.91 \%$ & 0.27 & 7.67 \\
\hline C/C CTA EW Diversified & $1 / 31 / 2001$ & $12 / 31 / 2010$ & 120 & $0.86 \%$ & $3.18 \%$ & 0.29 & -0.05 \\
\hline C/C CTA EW Systematic & $1 / 31 / 2001$ & $12 / 31 / 2010$ & 120 & $0.69 \%$ & $2.77 \%$ & 0.22 & -0.22 \\
\hline \multirow[t]{3}{*}{ C/C CTA EW } & $1 / 31 / 1990$ & $12 / 31 / 2010$ & 252 & $0.78 \%$ & $2.67 \%$ & 0.51 & 0.51 \\
\hline & $1 / 31 / 1990$ & $12 / 31 / 2000$ & 132 & $0.82 \%$ & $2.82 \%$ & 0.63 & 0.88 \\
\hline & $1 / 31 / 2001$ & $12 / 31 / 2010$ & 120 & $0.73 \%$ & $2.51 \%$ & 0.32 & -0.21 \\
\hline \multirow[t]{2}{*}{ Eureka CTA/Mgd Fut HF } & $1 / 31 / 2000$ & $12 / 31 / 2010$ & 132 & $1.05 \%$ & $2.25 \%$ & 0.43 & 0.50 \\
\hline & $1 / 31 / 2001$ & $12 / 31 / 2010$ & 120 & $1.00 \%$ & $2.17 \%$ & 0.21 & 0.02 \\
\hline \multirow[t]{2}{*}{ Eureka CTA FoF } & $1 / 31 / 2000$ & $12 / 31 / 2010$ & 132 & $0.68 \%$ & $2.36 \%$ & 0.14 & 0.36 \\
\hline & $1 / 31 / 2001$ & $12 / 31 / 2010$ & 120 & $0.60 \%$ & $2.30 \%$ & -0.03 & 0.13 \\
\hline \multirow[t]{2}{*}{ Eureka Global CTA FoF } & $1 / 31 / 2000$ & $12 / 31 / 2010$ & 132 & $0.62 \%$ & $2.38 \%$ & 0.10 & 0.23 \\
\hline & $1 / 31 / 2001$ & $12 / 31 / 2010$ & 120 & $0.57 \%$ & $2.35 \%$ & -0.03 & 0.06 \\
\hline FTSE Hedge CTA & $1 / 31 / 1998$ & $3 / 31 / 2009$ & 135 & $0.69 \%$ & $4.03 \%$ & 0.32 & 0.01 \\
\hline HFRX Macro: Active Trading & $1 / 31 / 2005$ & $12 / 31 / 2010$ & 72 & $0.68 \%$ & $1.45 \%$ & -0.88 & 2.95 \\
\hline $\begin{array}{l}\text { HFRX Macro: Discretionary } \\
\text { Thematic }\end{array}$ & $1 / 31 / 2005$ & $12 / 31 / 2010$ & 72 & $0.68 \%$ & $2.81 \%$ & -0.47 & 1.39 \\
\hline $\begin{array}{l}\text { HFRX Macro: Systematic } \\
\text { Diversified CTA }\end{array}$ & $1 / 31 / 2005$ & $12 / 31 / 2010$ & 72 & $0.77 \%$ & $3.22 \%$ & 0.51 & 0.44 \\
\hline \multirow[t]{2}{*}{ Newedge CTA } & $2 / 29 / 2000$ & $12 / 31 / 2010$ & 131 & $0.58 \%$ & $2.63 \%$ & 0.16 & 0.52 \\
\hline & $1 / 31 / 2001$ & $12 / 31 / 2010$ & 120 & $0.57 \%$ & $2.52 \%$ & -0.16 & 0.20 \\
\hline Newedge Commodity Trading & $1 / 31 / 2000$ & $6 / 30 / 2010$ & 126 & $1.47 \%$ & $3.24 \%$ & 0.57 & 1.06 \\
\hline S\&P HF Mgd Fut & $10 / 31 / 2002$ & $4 / 30 / 2006$ & 43 & $0.62 \%$ & $1.42 \%$ & -0.36 & 0.04 \\
\hline \multirow[t]{2}{*}{ Tuna CTA/Mgd Fut Avg } & $1 / 31 / 1990$ & $7 / 31 / 2009$ & 235 & $1.27 \%$ & $3.32 \%$ & 0.80 & 2.04 \\
\hline & $1 / 31 / 1990$ & $12 / 31 / 2000$ & 132 & $1.69 \%$ & $3.84 \%$ & 0.67 & 1.37 \\
\hline
\end{tabular}

Notes: 1. All statistics shown are based on monthly data. 2. Abbreviations: $\mathrm{C} / \mathrm{C}=\mathrm{CASAM} / \mathrm{CISDM}, \mathrm{AW}=\mathrm{Asset} \mathrm{Weighted}, \mathrm{EW}$ $=$ Equal Weighted, $\mathrm{HF}=$ Hedge Fund, FoF $=$ Fund of Funds, Eureka = Eurekahedge, MGD FUT or Mgd Fut $=$ Managed Futures . 


\section{NOTES}

